\title{
Investigate the Impact of Using Computer on Learning English for Specific Purposes of Management Students of Payame Noor Universities in Kashan
}

\author{
Mahdieh Razi ${ }^{1}$ \\ Javad Shekarriz² \\ Davood Kianoosh*3 \\ Mohammad Solooki ${ }^{1}$ \\ ${ }^{1}$ Department of Management, Faculty of Human Science, University of Kashan, Kashan, Iran \\ ${ }^{2}$ Department of Management, Faculty of Management, Payam-e-Noor University of Barzok, Barzok, Iran \\ ${ }^{*}$ Department of Accounting, Natanz Branch, Islamic Azad University, Natanz, Iran \\ *Corresponding author: Davood Kianoosh, E-mail: kianoosh.iau@gmail.com
}

\section{Doi:10.5901/mjss.2015.v6n6s1p151}

\section{Abstract}

\begin{abstract}
The main purpose of educational technology is to develop, ameliorate, and facilitate the process of learning and teaching. The technology of teaching English is one of the achievements of information and communication technology and in Humanities especially in Management which has its own specified theoretical framework and principles. The present research aimed to investigate the impact of using computer on learning English for specific purposes of management students of Payame Noor Universities in Kashan. The study enjoyed survey correlation method. The population of the study encompassed 741 management students (all disciplines) from Kashan and its suburbs (Kashan, Aran O Bidgol, Barzok, and Ghamsar). From among this population 210 students were singled out by accidental sampling as the main sample. A questionnaire, whose reliability and validity were already corroborated by the experts of management, computer and English, was used to gather data. Cronbach's Alfa was also used to approve the reliability of the questionnaire. To arrive at the answer to the research question of how computers effect English learning of management students at the Universities of Payame Noor, it was ascertained that there were significant interfaces between the investigated variables. The amount of correlation ( $=0.733)$ was strong which evinced the fact that computers have a high impact on learning English among the students of management. Paying attention to the results of the present research certifies that IT, communication, and concomitantly attention to English learning/teaching especially English for specific purposes, should be set more intensively in students' curriculum and educational planning.
\end{abstract}

Keywords: Education, Internet, Students of Management, English Language, Computer

\section{Introduction}

Numerous studies on further development of countries implies that information technology plays a critical role in the process of countries progression. Over the past decades, major advances have occurred to achieve education revolution, and it is predicted that over the next few decades, the phenomenon of computer technology maintain its role as the main factor of innovation in the world education (Jalali and Abbasi, 2003). One of the main topics in the humanities is Computer technology for teaching and learning language and various definitions are provided that they have a lot in common.

Accordingly one of the best definitions is given by Habbard. He states that the technology of teaching English is an interdisciplinary and research-based science which comprises met linguistic discourse, appropriate system of curriculum, regular and coherent standards of evaluation, as well as the proper facilities for teachers and students. Due to the rapid pace of globalization and to achieve more coalition (Global village) in education and economics, more association than ever before is required, especially in management majors which entail external communication and multinational forces at work to attain the goals of comparative management(Yaghoubi et al, 2008). 


\section{Research Background}

Given the development of information technology and the widespread use of computers in teaching and learning in universities, many researches were carried out in this arena. Some of them which are in close similarity to present study will be presented shortly:

Paraskeva (2008) examined the relationship between individual characteristics of secondary school teachers in Greece and computer self-efficacy as well as teacher prospects concerning modern technologies. This study revealed that previous prospect of the teachers with regard to the computer technology is the greatest factor in developing a positive attitude toward their use. Also providing useful software for each lesson would increase the use of computers effectively.

Green (2001) demonstrated that the attitude of faculty members, a significant factor in the use of technology and the computer, is determined by their personality and demographic characteristics. According to him, individuals who used the Internet for research purposes were from junior faculty members.

A study conducted by Garcia and Wingenbach (2004) in Texas University showed that internet usage was highest among the junior faculty members. Yet, some professors were old fashion and believed the Internet was not the best tool to conduct research.

Saadé et al (2007) argue that the faculty members' skills and attitude toward using technology in education are effective points. For that matter, personality factors i.e. attitude, educational interests and organizational support as well as the financial resources, are important in use of this technology.

Yaghoubi et al, (2008) in their major study, " Desired Characteristics of Faculty Members and Students in ELearning in Higher Education of Iran: Virtual Students' Viewpoint ", argue that five most highly ranked items on requirements for students into e-learning were identified as: responsibility, participation and creativity, IT skills, motivation and virtual ability.

Mohammadi (2008) in his study entitled "The impact of ICT in teaching and learning" states that Approaches and Methods in Language Teaching and the technology of learning language have many points in common; that is to say there is a positive and significant relationship between them.

Bazargan et al (2012) in his study, "Investigation the Relationship between ICT Utilization and Academic Performance of Faculty Members of Faculty of Psychology and Education of University of Tehran", demonstrates that there is a significant relationship between using the information technology by the faculty members and their performance.

So, the main question that will be examined in this paper is: "is there any significant interface between learning specialized English for management and the use of computer in Payame Noor Universities (PNU) of Kashan?"

\section{Methodology}

In order to assess the impact of computer on learning specialized English for the students of management in universities of Kashan, the survey correlation method was chosen.

Data were collected using a questionnaire, whose reliability and validity were already approved by the experts of management, Computer and English language. Concomitantly Cronbach's alpha was used to estimate the reliability of the questionnaire.

The Statistical population consisted 460 students of management students of Kashan of whom 210 students were recruited as a random sample. analysis.

Ordinal scale was performed to measure the variables of the research and also SPSS software used for statistical

The study was performed at autumn of 2014 in Payame Noor universities of Kashan.

\section{Results}

\subsection{Characteristics of the respondents}

Gender: $29.9 \%$ of respondents were male and 70.1 female, and $7 \%$ did not answer the gender question.

Age: Among 210 respondents, 3\% aged below 19, 62.7\% aged 19-22, 13.9\% aged 22-25, 9\% aged above 25 and $7 \%$ did not answer this question.

Employment status: Among respondents, $37.8 \%$ were both educating and employed, $19.4 \%$ were unemployed and 
looking for job, 35.8\% preferred educating only and $7 \%$ did not answer this question.

\subsection{Specific Characteristics of respondents in term of access to the internet}

The Access to the internet at home: Among total respondents, $36.4 \%$ had low access, $26.6 \%$ moderate, $37 \%$ high access at home and $4.5 \%$ did not answer this question.

The access to the Internet at work (education): Among total respondents, $67 \%$ had low access, $16.4 \%$ moderate and $10 \%$ high access to the Internet at work or education center. $12.9 \%$ did not answer the question.

The access to the Internet in the residence: Among all respondents, $24.4 \%$ had low access, $19.9 \%$ moderate and $41.3 \%$ high access to the Internet in their residence, while $14.4 \%$ did not answer the question.

\subsection{Specific Characteristics of respondents in term of learning English}

Care for learning English: Of all respondents, $69.7 \%$ did not care about learning English, while $22.9 \%$ concerned learning English. 7.5\% of respondents did not answer this question.

The Attractiveness of English: Among the sample population, $67.6 \%$ were interested in English, while $4.5 \%$ were opposed to the attractiveness of English and 3.5\% were abstention. 24.4\% did not respond to this question.

Learning English due to being international: $5 \%$ of the respondents were opposed to and $65.7 \%$ were agreed on this case, $5 \%$ were abstention and 24.4 did not answer this question.

Learning English Due to the business (education) need: $5 \%$ of the respondents were opposed to and $64.6 \%$ were agreed on this case, and $8 \%$ were abstention. Also $22.4 \%$ did not answer this question.

The attitudes of students toward English language skills: Among the total respondents, $63.7 \%$ were interested in vocabulary, $12.9 \%$ in Grammar and $12.9 \%$ in pronunciation. $10.4 \%$ did not answer this question.

The difficulty of Language skills for the students: $11.9 \%$ of students had problem in reading skill, $17.4 \%$ in writing, $15.4 \%$ in listening, and also $50.2 \%$ in speaking. $5 \%$ did not answer this question.

\subsection{Specific Characteristics of respondents in term of Computer-assisted language learning}

Learning English through the computer: $31.8 \%$ of the respondents never used it, compared to $6.5 \%$ who said often used it, $29.4 \%$ who used it sometimes, and $28.4 \%$ who used it rarely. $4 \%$ did not answer this question.

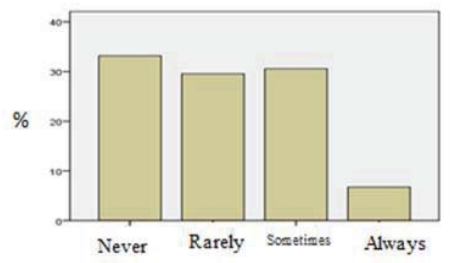

Learning English through the Internet: $33.3 \%$ of the respondents never used Internet to learn English, relative to $4.5 \%$ who said often used it, $19.4 \%$ who used it sometimes, and $34.3 \%$ who used it rarely. $8.5 \%$ did not answer this question.

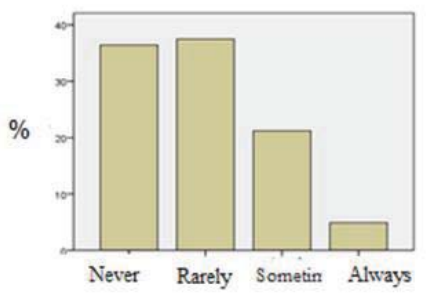

Membership in websites for learning English: $8 \%$ of the respondents were members of the aforementioned websites while $82.6 \%$ were not. $9.5 \%$ did not answer this question. 


\section{Data Analysis of Results}

Table 1. Internet Usage Index

\begin{tabular}{|l|c|c|c|c|c|c|c|}
\hline & Mean & Median & Variance & Standard deviation & Skewness & Kurtosis & Range \\
\hline frequency of The Internet(percentage) & 29.9470 & 27.7778 & 390.915 & 1.97716 & .798 & 1.011 & 100 \\
\hline
\end{tabular}

The Internet usage index comprises of 14 items obtained using mathematics (addition of items, and computing whose mean and coefficient, respectively); accordingly the data would seem to suggest the Internet access and use of each respondent.

The mean frequency of the Internet is 29.94 and the median and variance are 27.77 and 390.915 respectively. The standard deviation is 1.97716 ; that is to say $68 \%$ of the respondents got the mark in the range of 28.8 to 29.74 . Also the Skewness and kurtosis are .789 and 1.011 respectively.

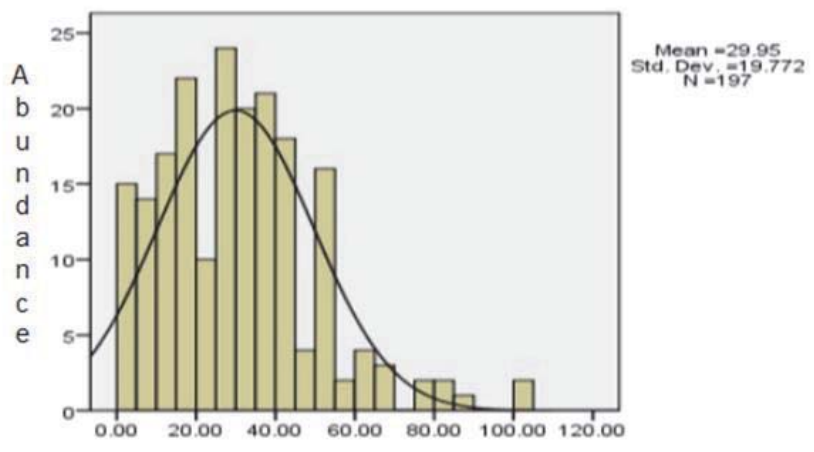

\subsection{The ranking Index of the Internet}

The index marks were assigned in a rank showing that $55.3 \%$ are in low ranking and $39.6 \%$ in normal and $5.1 \%$ in high ranking in terms of internet index.

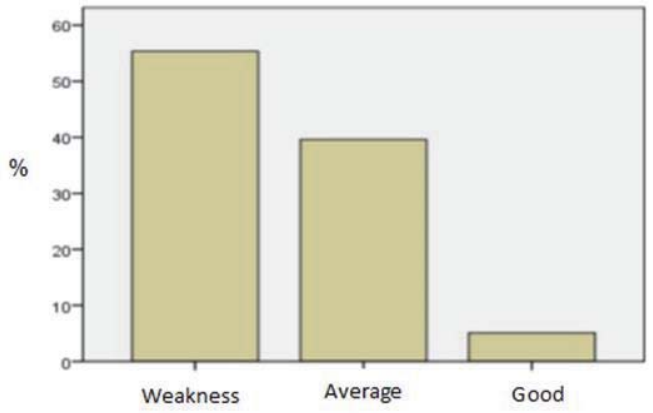

Table 2. The English Language Index

\begin{tabular}{|l|c|c|c|c|c|c|c|}
\hline & Mean & Median & Variance & Standard deviation & Skewness & Kurtosis & Range \\
\hline The index of the English(percentage) & 60.1 & 61.29 & 509.06 & 2.25 & -.084 & -.342 & 100 \\
\hline
\end{tabular}

The index mean of the English, median and the variance are $60.1,61.29$ and 509.06 respectively. The deviation standard is 2.25 showing that $68 \%$ of the respondents mark were in the range of $(60.01-2.25)$ to $(60.01+2.25)$. 


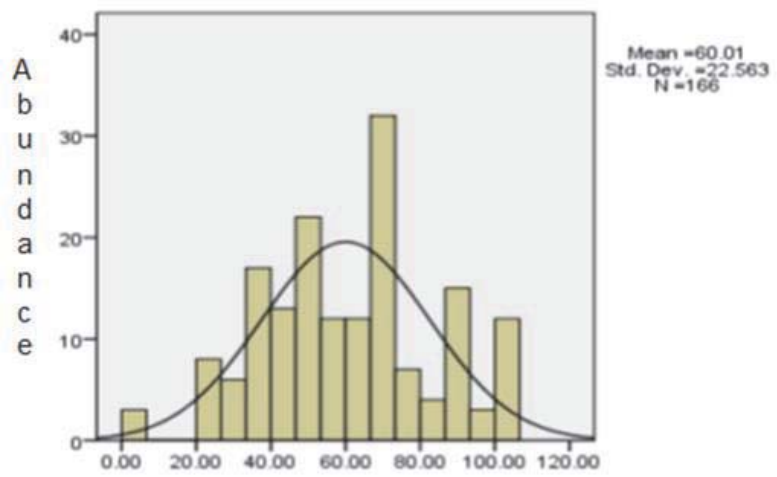

\subsection{The Ranking Index of English}

The ranking index of English shows that $10.2 \%$ of the respondents were in low ranking, $63.2 \%$ in normal and $44 \%$ were in high ranking in terms of English language.

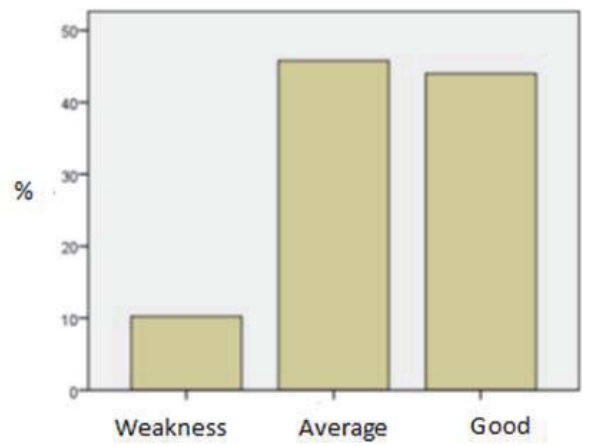

To arrive to conclusion in connection with the main purpose of this study which is to investigate the interface between learning English and the use of computer, firs of all we use the scatter diagram.

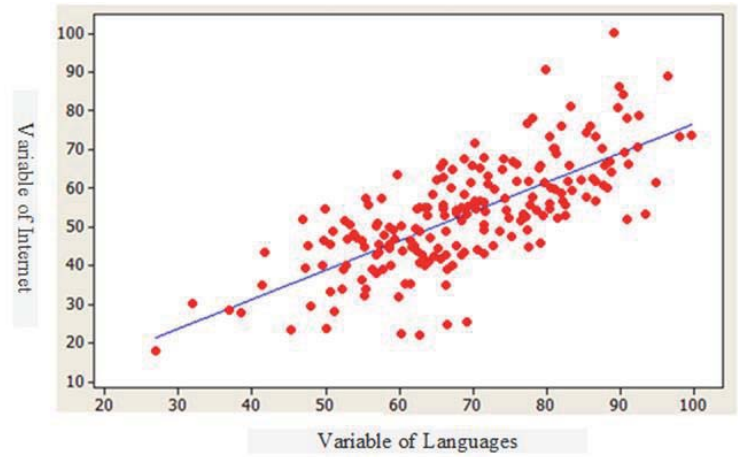

According to the diagram and concerning the relative dot density, it is apparent that there is a significant interface between the variables of the research (English and Computer); while the low density of dots around the regression line 
suggests the weak correlation between variables, but then again the fact remains that assuming strong correlation between variables in the human research areas is not reasonable. In the following the Pearson method is used to examine the generalizability of the study's results.

Table 3. Results of Pearson method

\begin{tabular}{|c|c|l|l|}
\hline The index of the English(percentage) & The index of the Internet(percentage) & & \\
\hline $0.733^{* *}$ & - & The Pearson correlation & \multirow{2}{*}{ The index of the Internet(percentage) } \\
\hline 000 & - & Sig. (2-tailed) & \\
\hline- & $0.733^{* *}$ & The Pearson correlation & \multirow{2}{*}{ The index of the English(percentage) } \\
\hline- & .000 & Sig. (2-tailed) & \\
\hline
\end{tabular}

As shown in the above table, Sig. (2-tailed) values lesser than 0.05 , indicating that there is positive answer on the research question, in other word; there is a significant interface between variables while the correlation value (0.733) is weak.

\section{Conclusion}

The computers and information technology has significant impacts on every aspect of Social activities, especially in learning language. Aiken and Aditya (1997) believe that information technology should be brought to the traditional classrooms in order to get familiar with the real world. Despite the fact that Information technology has provided new facilities for learning English, it has its own problems as well. For instance, not all the institutions have the same access to the technology and modern facilities and also not all the students have access to computers at home.

The facts and information bearing out nowadays have been challenging for education in general and particularly for learning language. The introduction and establishment of the communication and information technology have had a considerable impact on the evolution of various aspects of the education system, as resulted in new sorts of activities, implications and terminology. First of all the teachers and authors of the course-books need to have the new skills and attitudes in order to exploit the technology.

Due to the pioneering of the computer technology in learning language, it has become a decentralized pattern and includes several factors such as learning areas, learning horizon and the cognitive technology. These factors improve the cognitive and metacognitive skills of the teachers and students. If the one's metacognitive skills are improved, one would come to the independent learning process. It has major importance in learning language, since the major part of the language learning process is done individually, Independent and continuous and is not limited to place and time and the technology provides a great chance for it to be done. Teaching and learning language technology has the multidimensional nature and its designers have a process-oriented approach.

The foregoing study has attempted to examine the interface between learning English and the use of computer technology. From the observed weak correlation between learning English and computer technology we can conclude that information and communication technology, and concomitantly attention to learning English especially English for specific purposes, should be set more intensively in students' curriculum and educational planning. Considerably more attempts and attention by the experts and the members of the educational departments is required to fulfill this goal.

\section{References}

Aiken, R. M., \& Aditya, J. N. (1997). The golden rule and the ten commandments of teleteaching: harnessing the power of technology in education. Education and Information Technologies, 2(1), 5-15.

Bazargan, A., Hoseiny, A., and Mahdiuon, R. (2012). Investigation the Relationship between ICT Utilization and Academic Performance of Faculty Members of Faculty of Psychology and Education of University Of Tehran. Journal of Academic Librarianship and Information Research, 46(60): 13-30.

Garcia, J., and Wingenbach, G. (2004). Integration use in the Texas Mexico initiative. In Proceeding of the 20th annual Conference of the Association for International. Dublin, Ireland: Texas A \& M University Department of Agricultural Education. 598-603.

Green, K. C. (2001). The 2001 national survey of information technology in US higher education. The Campus Computing Project,< http://www. campuscomput ing. net/> (accessed February 10, 2007).

Jalali, A. A., and Abbasi, M. A. (2003). The information and communication technology in education systems of other countries. The third conference of the curriculum in the age of information and communication technology, Tehran, Iran.

Mohammadi, A. M. (2008). The impact of ICT in language teaching and learning. The research of foreign languages Quarterly, 15: 115139. 
Paraskeva, F., Bouta, H., \& Papagianni, A. (2008). Individual characteristics and computer self-efficacy in secondary education teachers to integrate technology in educational practice. Computers \& Education, 50(3), 1084-1091. doi:10.1016/j.compedu.2006.10.006

Saadé, R., Nebebe, F., \& Tan, W. (2007). Viability of the" Technology Acceptance Model" in multimedia learning environments: A comparative study. Interdisciplinary Journal of E-Learning and Learning Objects, 3(1), 175-184.

Yaghoubi J, Malek Mohammadi I, Iravani H, Attaran M. (2008). Desired Characteristics of Faculty Members and Students in E-Learning in Higher Education of Iran: Virtual Students' Viewpoint. Quarterly journal of Research and Planning in Higher Education, 14(1): 160-173. 